\title{
Global warming's five Germanys: A typology of Germans' views on climate change and patterns of media use and information
}

\author{
Metag, Julia ; Füchslin, Tobias ; Schäfer, Mike S
}

\begin{abstract}
People's attitudes toward climate change differ, and these differences may correspond to distinct patterns of media use and information seeking. However, studies extending analyses of attitude types and their specific media diets to countries beyond the United States are lacking. We use a secondary analysis of survey data from Germany to identify attitudes toward climate change among the German public and specify those segments of the population based on their media use and information seeking. Similar to the Global Warming's Six Americas study, we find distinct attitudes (Global Warming's Five Germanys) that differ in climate change-related perceptions as well as in media use and communicative behavior. These findings can help tailor communication campaigns regarding climate change to specific audiences.
\end{abstract}

DOI: https://doi.org/10.1177/0963662515592558

Posted at the Zurich Open Repository and Archive, University of Zurich

ZORA URL: https://doi.org/10.5167/uzh-148297

Journal Article

Published Version

Originally published at:

Metag, Julia; Füchslin, Tobias; Schäfer, Mike S (2017). Global warming’s five Germanys: A typology of Germans' views on climate change and patterns of media use and information. Public Understanding of Science, 26(4):434451.

DOI: https://doi.org/10.1177/0963662515592558 


\title{
Global warming's five Germanys: A typology of Germans' views on climate change and patterns of media use and information
}

Public Understanding of Science 2017, Vol. 26(4) 434-45। (C) The Author(s) 2015 Reprints and permissions: sagepub.co.uk/journalsPermissions.nav DOI: $10.1177 / 0963662515592558$ journals.sagepub.com/home/pus

@SAGE

\section{Julia Metag, Tobias Füchslin and Mike S. Schäfer}

University of Zurich, Switzerland

\begin{abstract}
People's attitudes toward climate change differ, and these differences may correspond to distinct patterns of media use and information seeking. However, studies extending analyses of attitude types and their specific media diets to countries beyond the United States are lacking. We use a secondary analysis of survey data from Germany to identify attitudes toward climate change among the German public and specify those segments of the population based on their media use and information seeking. Similar to the Global Warming's Six Americas study, we find distinct attitudes (Global Warming's Five Germanys) that differ in climate change-related perceptions as well as in media use and communicative behavior. These findings can help tailor communication campaigns regarding climate change to specific audiences.
\end{abstract}

\section{Keywords}

attitudes, audience segmentation, climate change, Germany, information, mass media, survey

\section{Introduction}

Climate change is one of the "defining issues of our age," according to United Nations (UN) General Secretary Ban Ki Moon (UN News Centre, 2014) and poses major political and societal challenges. Accordingly, the issue has a firm place on the public agenda in countries around the world (Schmidt et al., 2013), and many people hold strong views about these issues (European Commission, 2014; Nisbet and Myers, 2007). These public perceptions are important. They shape how individuals react to climate change and, ultimately, influence political decision-making since the implementation of mitigation and adaptation policies such as carbon taxes or subsidies for renewable energies relies on public legitimation.

\section{Corresponding author:}

Julia Metag, IPMZ - Institute of Mass Communication and Media Research, University of Zurich, Andreasstrasse I5, $\mathrm{CH}-8050$ Zurich, Switzerland.

Email: j.metag@ipmz.uzh.ch 
The views people hold about climate change are (also) shaped by communication. Since climate change is an unobtrusive issue, that is, abstract, complex, and not directly perceivable (e.g. Moser, 2010), people's views are often based on information provided by the news media or interpersonal communication (e.g. Arlt et al., 2011; Leiserowitz et al., 2015; Schäfer, 2012).

Therefore, many studies have analyzed how and to what extent news media and interpersonal communication influence people's views on climate change (for overviews, see Schäfer, 2015; Taddicken, 2013). Researchers have shown that communication can affect knowledge about climate change (Taddicken, 2013; Zhao, 2009) as well as awareness (Arlt et al., 2011; Sampei and Aoyagi-Usui, 2009; Taddicken, 2013), and in some cases, even behavioral intentions or action (Arlt et al., 2011; Cabecinhas et al., 2008).

These studies use multivariate statistics to tease out differences among respondents' knowledge, attitudes, or behaviors along demographic, psychological, or media use variables. The studies do not, however, account for the fact that the public may be segmented regarding climate change, that distinct attitude types may be distinguishable, and that the media use and communication patterns of these types may differ.

The best-known works demonstrating such segmentations are the Global Warming's Six Americas study by Anthony Leiserowitz et al. (2009, 2013a). They show, among other things, that US citizens' views on climate change differ strongly, and that these differences are accompanied by variations in the individuals' issue-specific media use and information seeking. People who doubt the existence of climate change rely on their friends and families for information while people who are "alarmed" about the issue use all mass media heavily (Leiserowitz et al., 2009: 28). Acknowledging and reconstructing such segmentation is not only relevant for the scientific community but is also crucial since communication campaigns can be designed to specifically address particular segments of the population (Hefner, 2013).

However, although the Global Warming's Six Americas study was recently extended to India (Leiserowitz et al., 2013b) and Australia (Morrison et al., 2013; Sherley et al., 2014), it is still unclear whether similar segments exist in other countries, to what extent the segments mirror Leiserowitz et al.'s (2009) typologies, and whether they correspond with specific patterns of information and media use in other countries.

This study aims to remedy these shortcomings. It uses data from a survey on Germans' views about climate change and presents a secondary analysis of this data in which most of the analytical dimensions relevant in the literature can be operationalized. We analyze whether the German population can be grouped into typologies similar to the typologies shown in the United States and India and whether corresponding differences in media and communication patterns are discernible. Germany is an interesting case for this analysis since the German context differs from the US context: the level of climate change skepticism is much lower than in the United States (Engels et al., 2013), the existence of climate change has been accepted more widely, and relatively broad consensus exists that political measures are necessary (Peters and Heinrichs, 2008).

\section{Conceptual framework}

\section{Existing typologies and their usefulness}

Typologies aim to condense different characteristics of their analytical objects in order to elucidate latent patterns. In doing so, typologies achieve something linear statistical analysis such as regression analysis does not: they allow researchers to identify homogeneous groups of people across different characteristics. 
When it comes to attitudes toward climate change, the leading study is the Global Warming's Six Americas (Leiserowitz et al., 2013a, 2014). Based on surveys of the US population, the study identified six segments among respondents regarding climate change: the Alarmed, who are most engaged about global warming; the Concerned, who are convinced that global warming exists but are less involved; the Cautious, who are less certain and do not view global warming as a personal threat; the Disengaged, who have not put much thought into the issue of climate change at all; the Doubtful, who are split between people who believe that climate change exists but that natural changes are responsible and those who do not believe in it; and the Dismissive, who are engaged because they strongly believe that global warming is not happening (Leiserowitz et al., 2009: 3-4). In October 2014, the Concerned (31\%) and the Cautious (23\%) formed the largest part of the US population. The Disengaged constituted the smallest group, $7 \%$ of the population (Leiserowitz et al., 2014). Apart from distinguishing these "Six Americas," the study also showed how these groups differ in media use and information seeking. For example, the Alarmed are higher than average media users while the Dismissive mainly rely on their friends and families for information about climate change (Leiserowitz et al., 2009).

Thus far, the Six Americas study is the only one presenting such a typology for climate change and supplementing it with media use and information-seeking patterns. When the project was extended to India and to Australia - revealing that both populations could be segmented into Global Warming's Six Indias (Leiserowitz et al., 2013b) and Six Australias, respectively (Morrison et al., 2013) — neither study included media use or information seeking.

Similar studies exist for other related issues such as environmental or energy topics. Among these studies, however, Hefner's (2013) study is the only one that included media use and information seeking. She presents six types into which the German public can be grouped regarding their environmental attitudes and behavior, ranging from people who are highly concerned but do not exhibit environmentally friendly behavior to people who are not concerned at all. Using cluster analysis, she shows that these types also differ in communicative behavior and information gathering. For example, environmentally concerned people use quality newspapers more often, while the less environmentally concerned rely mostly on television.

Many other studies have proposed attitude-based typologies for countries other than the United States or Germany focused on environmental or energy questions. None, however, include media or communication variables. Sütterlin et al. (2011) analyze Swiss views on energy consumption. Similar to Leiserowitz et al. (2009) and Hefner (2013), the researchers show that the Swiss public can be segmented into six types based on energy-related behavioral characteristics, such as the idealistic type who performs the most energy-saving efforts or the convenience-oriented indifferent energy consumers who are ignorant about the increase in energy consumption and are least likely to change their behavior (Sütterlin et al., 2011). Another study distinguished three types of people in Portugal regarding recycling: One is positive about it, and two are reluctant or indifferent (Vicente and Reis, 2007).

In sum, these studies demonstrate that the population of different countries can be divided into distinct attitude types toward environmental and energy issues. This seems to apply to climate change as well, as the US, Australian, and Indian studies show. In addition, there is some evidence that these typologies correspond with different uses of media and other sources of information, that is, that the information-seeking patterns of people who have different attitudes differ systematically. However, whether such a typology for the case of climate change can be developed for countries other than the United States, Australia, and India, and whether it goes hand in hand with specific patterns of information and media use, remains to be shown.

Therefore, we pose the following research questions: 
$R Q 1$. Which segments of the German population can be distinguished regarding their attitudes toward climate change?

$R Q 2$. Do the media and communication patterns of these segments differ?

\section{Relevant dimensions for devising a typology of the German population}

First, we create a typology of the German public based on climate change-related variables. In the second step, we characterize these types in terms of their communication patterns. In doing so, we rely on analytical dimensions used in previous studies on attitudes toward climate change and integrate studies that deal with environmental and energy questions. These dimensions include the cognitive, affective, and conative aspects of attitudes (Ajzen, 1989):

- Concern about climate change. A core dimension in people's attitudes toward climate change is their concern. This dimension includes cognitive components such as the perception of climate change as a problem as well as affective components such as the perceived threat from climate change impact such as natural disasters (Arlt et al., 2011; Leiserowitz et al., 2009).

- Beliefs and issue involvement. Regarding attitudes toward climate change, it is also crucial to what extent someone believes that climate change is actually occurring (Engels et al., 2013; Leiserowitz et al., 2009). This can comprise a person's certainty or doubt (Leiserowitz et al., 2014), beliefs about climate science (McCright and Dunlap, 2011), and whether global warming poses a personal threat (Leiserowitz et al., 2009).

- Knowledge about climate change. Another dimension that captures the cognitive component of attitudes toward climate change is someone's knowledge of climate change. Here, people's factual knowledge can be distinguished from self-assessments of own knowledge (Taddicken, 2013). Factual knowledge is usually assessed with quiz questions about the causes and consequences of climate change (Cabecinhas et al., 2008; Taddicken, 2013), while self-assessments inquire whether people feel well informed about the issue (Leiserowitz et al., 2009).

- Climate change-related behavior. The behavioral component of attitudes can be measured as behavioral intentions or actual behavior (Leiserowitz et al., 2009). Arlt et al. (2011) conceptualize climate change-related behavioral intentions as the intentions of making investments to protect the environment, of changing one's lifestyle, and of being politically active in promoting climate protection. Taddicken (2013) differentiates between the willingness to take responsibility and the willingness to act related to climate change. Energy conservation actions are often described as actual behavior closely related to climate change (Leiserowitz et al., 2009, 2014).

- Policy preferences. The Global Warming's Six Americas study also focuses on the extent to which people support climate policies such as regulating $\mathrm{CO}_{2}$ emissions (Leiserowitz et al., 2009). The researchers assume that this attitudinal dimension is related to general beliefs about global warming.

Second, overarching values, such as attitudes toward the environment, as well as sociodemographics, are important for attitudes toward climate change (Taddicken, 2013):

- General environmental awareness. People who are aware of environmental problems tend to perceive climate change as a problem as well (Taddicken and Neverla, 2011). Awareness of environmental problems can be differentiated in self-oriented concern about environmental 
problems affecting one's own life and more general concerns (Hefner, 2013). Environmental awareness can also be understood as having affective, cognitive, and conative aspects (Diekmann and Preisendörfer, 2003).

- Values. Value orientations also influence climate change-related attitudes (Arlt et al., 2011; Engels et al., 2013). This includes basic values of freedom, equality, security, as well as altruism and hedonism (Arlt et al., 2011).

- Subjective norms. As studies on environmental awareness have shown, subjective normsperceived norms emerging from the behavior of people who are important to an individualcan influence attitudes (Bamberg and Möser, 2007). The same effect of subjective norms should also be discernable when climate change-related attitudes are concerned.

- Socio-demographics. Variables such as age, education, income, sex, or household size are also relevant for one's attitudes toward climate change (Leiserowitz et al., 2009; Taddicken, 2013) as well as toward environmental and energy issues (Hefner, 2013; Sütterlin et al., 2011).

We will use these dimensions to analyze if the German public is segmented regarding their attitudes toward climate change. In the second step, we scrutinize whether these segments differ in how they use mass media and interpersonal communication for information about climate change. Therefore, variables that capture mass media use and information seeking are the third group of factors considered in our analysis:

- Mass media use. As studies have demonstrated, the frequency of media use as well as the chosen media channel — newspapers, magazines, radio, or TV-can influence attitudes toward global warming (Arlt et al., 2011; Taddicken, 2013).

- Perceived quality of media outlets. Related to the use of mass media is how individuals perceive the quality of information they receive about climate change from the different media outlets. The higher the perceived quality, the more persuasive the pieces of information (O’Keefe, 1990).

- Interpersonal communication. Information about climate change can also be received through interpersonal contacts (Leiserowitz et al., 2015). The more people talk to others about climate change, the more information people get about climate change that can influence their own attitudes.

\section{Data and method}

\section{Data}

Our data stem from a nationwide representative telephone (computer-assisted telephone interviewing (CATI)) survey of 3000 Germans aged 18 years and older, funded by the University of Hamburg's Federal Research Cluster of Excellence (CliSAP) and conducted from April to June 2011. ${ }^{1}$ As Figure 1 shows, the survey was conducted during a period of moderate societal attention for climate change in Germany. Media attention - as measured by keyword searches in the five most important German daily newspapers and two weeklies — was at a medium level after a strong peak around the 15th Conference of the Parties (COP 15) in Copenhagen in 2009 (Schäfer et al., 2014). Google trends data, measuring Google search requests for these climate change-related keywords from 2004 to 2011, largely mirror the media attention. The Eurobarometer surveys on attitudes toward climate change indicate that most Germans saw climate change as a serious problem at the time but that these worries had decreased slightly in 2011. Although these data helpfully contextualize the situation in Germany regarding climate change, the audience segments we focus 


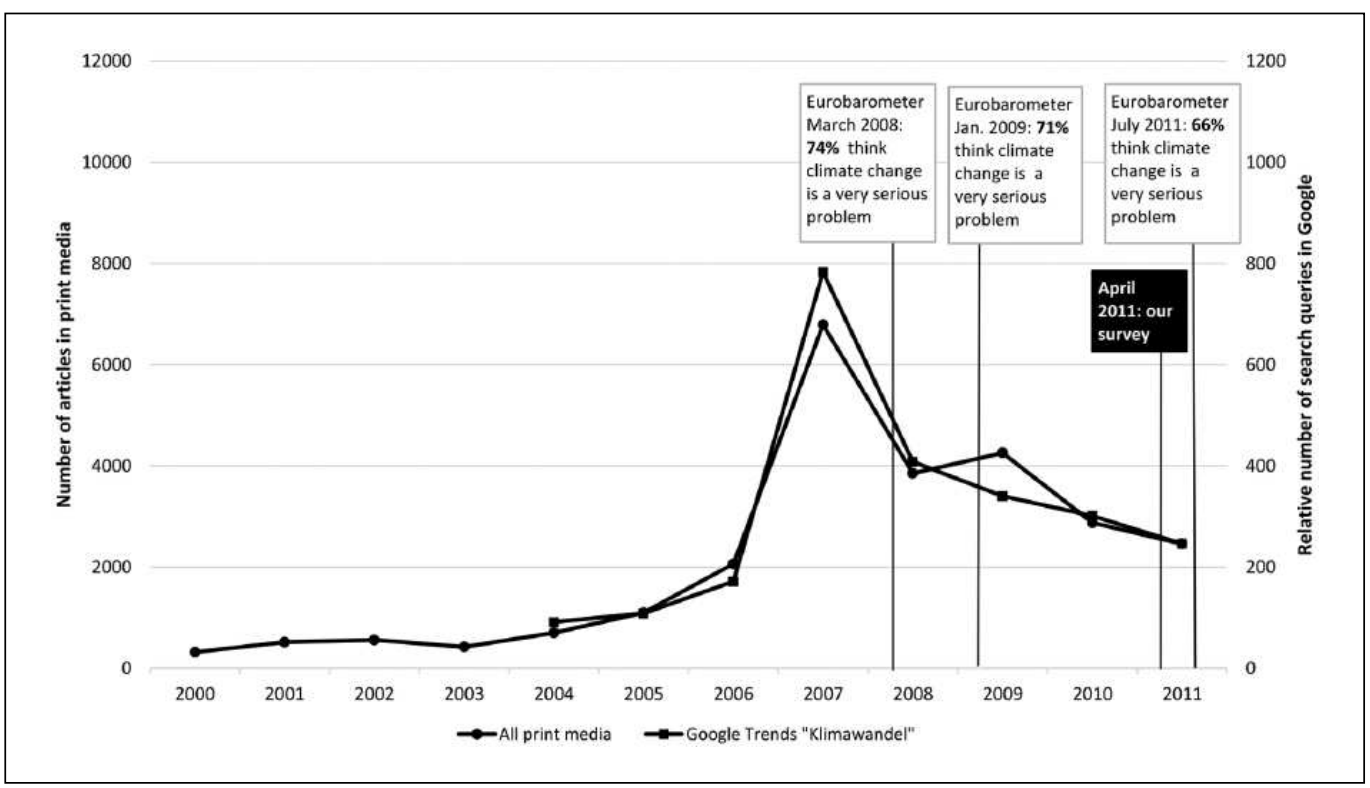

Figure I. Issue attention for climate change in Germany. Print media articles (daily newspapers: Süddeutsche Zeitung, Frankfurter Allgemeine, taz, Frankfurter Rundschau, Welt; weekly newspapers: Focus, Spiegel) were searched in archives using the search terms "Klimawandel or Erderwärmung or globale Erwärmung or Treibhauseffekt". Data from Eurobarometer surveys is used to depict the development of the public's attitudes towards global warming. Google trends results are used as a measure fur public attention (Google trends figures are relative in the sense that Google trends depicts how often a search term is searched for during a period of time in comparison to all other Google searches. Thus, the data is normalized on a scale from 0 to 100 . Each figure is divided by the maximum value and multiplied with 100. Google trends also only offers data back to 2004.)

on should be only slightly susceptible to changing contexts, since the segments are based on stable attitudes and values.

\section{Operationalization}

We aimed to operationalize as many of the relevant analytical dimensions for segmenting audiences according to their attitudes toward global warming that have been emphasized in the scholarly literature as possible. Since we performed a secondary analysis, however, we had to rely on the available survey questions. A total of 39 questions matched the dimensions outlined in section "Relevant dimensions for devising a typology of the German population" (see Table 1 for an overview). However, we did not capture all sub-dimensions that were part of the Global Warming's Six Americas or Australias studies.

We captured the following dimensions:

- Beliefs about climate change consist of multiple items. This dimension captures the direct acknowledgement of climate change as well as the role of climate science.

- To address general environmental awareness, multiple cognitive and affective items were used.

- We could not capture the subjective norm in its original sense but approximated it with two items that describe the urgency of collective action. In these items, however, the locus of control and who is supposed to act remain vague. 
Table I. Items used in our study and in reference studies.

Our survey

Beliefs about climate change

"Climate change is man-made." ( $\mathrm{I}=$ completely disagree to $5=$ completely agree; $M=4.0 \mathrm{I}, \mathrm{SD}=\mathrm{I} .05$ )

"Climate research is of the unanimous opinion that global warming is real." $(M=3.98, S D=1.06)$

"Climate change is currently happening." $(M=4.03, S D=0.94)$

"Industrial countries like Germany are predominantly responsible for climate change." $(M=3.24, S D=1.17)$

"Climate scientists can be trusted." $(M=3.27, S D=1.01)$

General environmental awareness

"Earth's living space and resources are highly limited." ( 1 = completely disagree to $5=$ completely agree; $M=4.28, S D=1.00$ )

"The scope of the ecological crisis is being exaggerated." $(M=2.78$, $S D=1.13$ )

"Earth's natural balance can withstand pollution." $(M=2.58, S D=1.15)$

"We are heading toward an environmental disaster." $(M=3.82, S D=1.16)$

"Human beings are damaging the environment seriously." $(M=4.35$, $S D=0.93)$

Urgency of collective action

"It's important to take measures against climate change as soon as possible." ( $I=$ completely disagree to $5=$ completely agree; $M=4.46, S D=0.89$ )

"If one acts immediately climate change can be averted. $(M=2.94$,

$S D=1.16$ )"

Value dimensions

"We live at the expense of future generations." $(M=3.97, S D=1.16)$

"In Germany, the enforcement of equal rights for everyone is being taken too seriously." $(M=2.83, S D=I .18)$

"Individual freedom is too restricted in today's society." $(M=2.91, S D=1.18)$

"Many problems can best be solved by individual people." $(M=2.82$,

$S D=1.30)$

"We are not doing enough to fight poverty in the world." $(M=3.54$, $S D=1.26)$

Concern about climate change

"Climate change is a serious problem." $(M=4.43, S D=0.89)$

"Climate change causes an increase in extreme weather events."

$(M=4.34, S D=0.90)$

"I'm seriously worried about climate change." $(M=3.79, S D=1.17)$

Personal affectedness by the worst impacts of climate change

( $I=$ yes to $2=$ no; $M=I .36, S D=0.48$ )

Region which has been most negatively impacted by climate change

( $I=$ close by to $5=$ far away/other part of world; $M=4.36, S D=0.99$ )

Knowledge of climate change

"How well informed are you about climate change?" ( I = not at all to

$5=$ very well; $M=3.48, S D=0.74$ )
Global Warming's Six Americas

(Maibach et al., 20I I), also used in

Australia (Morrison et al., 2013)

Global warming beliefs

Certainty global warming is occurring Human causation (\% agree)

Scientific consensus (\% agree)

Personal risk

Risk to future generations

Risk to plant and animal species

Timing of harm to Americans

Ability of humans to successfully mitigate climate change

Actions of individuals can make a difference

Technological optimism

Perceived impact of own mitigation actions

Impact of own actions if widely adopted in the United States Impact of own actions if widely adopted in modern industrialized countries
Global warming issue involvement

Rating of global warming ( $I=\operatorname{good}$ to $6=$ bad)

Worry about global warming

Thought given to global warming Need for information (4=low need) Personal importance of issue Unwilling to change opinion Personally experienced global warming Global warming discussion frequency Friends share views on global warming

Global warming and energy efficiency and conservation behaviors Contacted govt officials about mitigation

Rewarded companies that reduced emissions 
Table I. (Continued)

Our survey

Global Warming's Six Americas

(Maibach et al., 20I I), also used in

Australia (Morrison et al., 20I3)

Do you have an electricity rate that is fully or partly powered by ecological energy sources? $(I=$ yes to $0=n o ; M=0.60, S D=0.49$ )

Intend to reward companies that reduce emissions

Car use for shopping ( $I=$ never to $6=$ daily; $M=3.93, S D=I .40)$

Punished companies that are not

Car use for leisure activities $(M=3.64, S D=1.49)$

Car use for driving to work $(M=3.94, S D=2.28)$

Number of cars in household $(M=1.35, S D=0.84)$

Kilometers per week by $\operatorname{car}(M=225.73, S D=422.47)$

reducing emissions

Intend to punish companies that are

not reducing emissions

Political activism

Stage of change for lowering

thermostat in winter

Actively collecting signatures regarding energy issues $(0=$ wouldn't ever to

$\mathrm{I}=$ have done/might do; $M=0.5 \mathrm{I}, \mathrm{SD}=0.50$ )

Participation in citizens' initiative regarding energy issues $(M=0.66$, $S D=0.47$ )

Participation in demonstrations regarding energy issues $(M=0.43$, $S D=0.50)$

Joining an environmental organization $(M=0.45, S D=0.50)$

Signing a petition regarding energy issues $(M=0.82, S D=0.38)$

Donation for environmental organization $(M=0.67, S D=0.47)$

Stage of change for using public transportation or car pool Stage of change for walking/biking instead of driving

Stage of change for CFL use

Mass media use and information seeking

How often do you hear about climate change from the following sources? Television $(M=4.33, S D=1.02)$, radio $(M=3.75, S D=1.40)$, tabloids $(M=2.64, S D=1.56)$, other daily newspapers $(M=3.76, S D=1.39)$, weekly magazines and newspapers $(M=3.62, S D=I .42)$, Internet $(M=3.45$, $S D=1.24)$, conversations with friends and family $(M=4.33, S D=1.02)$; I = never to $5=$ every week

On which source would you rely the most if in doubt? Television (38\%), radio $(7 \%)$, tabloids $(0.3 \%)$, other daily newspapers (15\%), weekly magazines and newspapers (14\%), Internet (17\%), conversations with friends and family $(8 \%)$

To what extent would you say that this characteristic applies to this source: actuality $(M=4.33, S D=0.79) /$ preciseness $(M=3.91, S D=0.87)$ / balance $(M=3.7 \mathrm{I}, S D=0.94) /$ truthfulness $(M=3.43, S D=0.88)$ ? I = not at all to $5=$ very much
Preferred societal response to global warming

Priority of global warming for president and Congress Corporations should do more/less to reduce warming

Citizens should do more/less to reduce warming

Desired US effort to reduce warming, given associated costs

Contingent int'l conditions for US mitigation action (\% regardless of actions in other countries)

Mass media use and information seeking How much attention do you pay to information about global warming? A lot to None

In the past 30 days, how often have you actively looked for information about global warming? A lot to None How much do you trust or distrust the following as a source of information about global warming? Strongly trust to Strongly distrust How many days per week do you read a printed newspaper/listen to the radio ...?

How often do you watch or listen to the following shows or visit their websites? Often to Never

SD: standard deviation; CFL: compact fluorescent lamps.

The items used in the survey for the Six Indias are also available in Leiserowitz et al.'s (20I3b) report. We refrain from listing them here as India as a developing country is very different from the United States, Australia, and Germany, and thus, the survey was adapted more intensively to this specific country. 
- Several items covered value dimensions. These values are not ideological values but general values about how a society should function and whether one prefers individualistic or collectivistic ways of living. People with collectivistic values have been shown to be more engaged in fighting climate change.

- Concern about climate change comprises items that cover cognitive and affective components asking about the respondents' concern about climate change.

- Knowledge of climate change could not be measured through questions that captured the respondents' factual knowledge about global warming but through one item that measured the participants' individual perception of their knowledge.

- Climate change-related behavior was predominantly captured through energy conservation items.

- Political activism was accounted for by numerous questions concerning past environmental activities in which people had participated.

These items were entered into factor analysis to establish the dimensions the items cover (see Hefner, 2013; Sütterlin et al., 2011), which were then used as discriminating variables in the subsequent cluster analysis. In addition, the respondents' use of information about climate change was measured:

- To measure mass media use, participants were asked how often they get information about global warming from different types of mass media. Among these outlets, participants were asked to name the most reliable one and then to rate it in terms of actuality, preciseness, balance, and truthfulness. These variables describe the perceived quality of media outlets. The question about the frequency of getting information about climate change included information from "conversations with friends and family" which allows us to measure interpersonal communication.

- Demographics included age, sex, income, education (highest degree), people per household, whether the respondents had children, and whether the respondents were employed.

\section{Typology}

To ensure a concise solution for the cluster analysis, the 39 items were condensed into fewer independent constructs using principal axis factor analysis. Missing values were ignored case wise, and variables with loadings on multiple factors and/or loadings below .4 were excluded. Some variables with low commonalities were also removed. This led to a robust solution consisting of 26 items representing seven factors: Concern about climate change, political activism on energy issues, car use in everyday life, ecological conservatism, environmental concern, abstention from longer car/ plane journeys, and the use of eco-power (see Online Appendix for a detailed overview of the items loading on each factor).

Based on these seven factors, a hierarchical cluster analysis was conducted with the remaining 1943 cases. $^{2}$ First, the single-linkage method was applied that identified six outliers, which were then excluded from the sample. Based on these data, the cases were clustered using the Ward method and the elbow criterion to identify the best solution. ${ }^{3}$ The five-cluster solution yielded the most differentiated coefficient and straightforward interpretation. A discriminant analysis was conducted to validate the cluster solution. The analysis yielded a rate of $81.1 \%$ of correctly identified cases, a value lower than those derived from content analytical data (e.g. Donk et al., 2012) but not atypical for attitude measures taken from survey data (Brosius, 2013). We also calculated $F$ and $t$ values that are helpful for interpreting which variables are distinctive for which cluster. 
Table 2. Audience segments and the climate change-related dimensions.

\begin{tabular}{lccccc}
\hline & Alarmed & $\begin{array}{l}\text { Concerned } \\
\text { activists }\end{array}$ & Cautious & Disengaged & Doubtful \\
\hline$N(\%$ of sample) & $459(24 \%)$ & $345(18 \%)$ & $543(28 \%)$ & $389(20 \%)$ & $201(10 \%)$ \\
\hline Concern about climate change & $\mathbf{0 . 4 1}$ & 0.13 & 0.16 & 0.18 & $-\mathbf{I . 6 0}$ \\
\hline Environmental concern & $\mathbf{0 . 4 5}$ & -0.02 & -0.14 & $-\mathbf{0 . 1 9}$ & 0.33 \\
\hline Car use & 0.05 & -0.04 & $\mathbf{0 . 4 9}$ & $-\mathbf{0 . 3 9}$ & 0.26 \\
\hline Abstention from longer car/plane journeys & $\mathbf{0 . 6 1}$ & 0.30 & $-\mathbf{0 . 6 5}$ & 0.45 & -0.15 \\
\hline Eco-power & $\mathbf{- 0 . 4 2}$ & $\mathbf{1 . 7 5}$ & -0.37 & -0.34 & -0.12 \\
\hline Political activism on energy issues & $\mathbf{0 . 6 1}$ & 0.28 & 0.30 & $-\mathbf{0 . 9 3}$ & -0.48 \\
\hline Ecological conservatism & $\mathbf{- 0 . 2 6}$ & -0.24 & $\mathbf{0 . 2 6}$ & 0.01 & 0.11 \\
\hline
\end{tabular}

$N=1937$. Lowest and highest scores per factor are shown in bold.

\section{Global warming's five Germanys: Results}

\section{Attitude types among the German population}

Table 2 shows that five clusters can be found among the German population. Similar to that of the United States, they span a broad range of attitudes. ${ }^{4}$

The first type, which we labeled the Alarmed $(n=459)$, scored the highest for being concerned about climate change and forms the second largest audience segment ( $24 \%$ of all respondents). The Alarmed are strongly concerned about climate change as well as the environment in general. Correspondingly, they are willing to abstain from longer car or plane journeys, do not use their cars more than averagely, and are politically active regarding energy issues. They are also the audience segment that most strongly believes ecological problems exist. However, although they are concerned about global warming and the environment, this concern does not extend to using eco-power.

The second cluster, the Concerned Activists $(n=345,18 \%)$, are concerned about climate change - albeit less so than the Alarmed - and translate this concern into action. Their overall values point to environmentally friendly attitudes, they refrain from using cars and planes for longer journeys, and they show an above-average political activism tendency. Compared to the other types, this group are the only ones willing to use eco-power and the audience segment with the most environmentally friendly behavior.

The Cautious ( $n=543,28 \%$ ) form the largest cluster. Although they appear to be concerned about climate change, their concern is not strong and does not translate into action. They use cars in everyday life, do not refrain from longer travel by car or plane, and do not use eco-power. We labeled them Cautious to convey their reluctance to behave in a climate-friendly manner (in the same way as Leiserowitz et al. (2009) used the label). The only aspect that mirrors their concern about global warming is their willingness to be politically active. This gap between attitude and behavior might be explained by the Cautious' conservative ecological values and their lack of worry about the environment in general. Although they are concerned about climate change, they do not strongly agree with statements that Earth's resources are limited or that we are living at the expense of future generations. This cluster, however, supports findings on climate change attitudes in Germany that show that although most citizens are convinced that climate change exists (Engels et al., 2013), this often fails to trigger corresponding behavior. 
The Disengaged ( $n=389,20 \%$ ) are similar to the Cautious, but their disengagement is stronger. They are concerned about climate change but show the lowest environmental concern, and their ecological attitudes are not pronounced. They are not likely to use eco-power or to be politically active regarding climate change or energy issues. Their distinctive characteristic is that they entail the lowest number of people who have or use cars and that they would refrain from longer car or plane journeys.

The smallest audience segment are the Doubtful $(n=201,10 \%)$. They are not concerned about climate change at all and are skeptical that it exists or that it is caused by humans. This is mirrored in their behavior; they are neither likely to be involved in political activism nor are willing to switch to eco-power, reduce plane or car journeys, or stop using their car in everyday life. Similar to the Doubtful in the United States (Leiserowitz et al., 2009), doubtful Germans are conservative. However, they are not as environmentally ignorant as one might expect, since they still tend to believe that Earth's resources are limited and that humans are living at the expense of future generations.

\section{Media use and information-seeking patterns}

Global Warming's Five Germanys differ not only in their attitudes toward climate change. The German segments also differ socio-demographically and, most importantly for us, use different channels of communication (Table 3).

The Alarmed. With an average age of 50 years, $48 \%$ male, medium income and education, and between two and three people per household, the Alarmed represent the average German citizen.

The Alarmed are most concerned about climate change and the environment. And they are willing to give up certain living conveniences to do something about climate change. This is mirrored in their information and communication behavior. They are eager to receive information about climate change and search for it most frequently and significantly more often than the Cautious, Disengaged, and Doubtful. Although television is the Alarmed's primary source, they use all kinds of media frequently. They believe that television is the most reliable medium for information about climate change because they attribute up-to-date and precise news coverage to television. Respondents in this cluster also talk to family and friends significantly most often about climate change.

The Concerned Activists. With an average age of 48 years, this is the youngest cluster in our sample; $54 \%$ are male. The share of employed people and, correspondingly, the average income are the highest among all clusters, also indicating that they can afford to use eco-power.

This group exhibits above-average concern about climate change and more activism, which goes hand in hand with intensive information seeking about global warming. Similar to the other clusters, they use television most intensely, followed by newspapers and radio. Compared to the other audience segments, except the Alarmed, the Concerned Activists use the Internet more frequently for information about climate change. That these people are generally well informed and rely on more than one source can also be shown by the fact that they think weekly newspapers and magazines are the second most reliable sources for information about climate change.

The Cautious. This cluster contains more men (55\%) than women, with an average age of 50 years, and a household size of three. Since $71.5 \%$ have at least one child, in this group, most respondents have children.

Although they are concerned about climate change, the Cautious scored only average in terms of information seeking about climate change. This is in line with their cautious, reluctant behavior regarding climate change. Among the five audience segments, this cluster uses television most 
Table 3. Communication variables and demographics of cluster types.

\begin{tabular}{|c|c|c|c|c|c|}
\hline & Alarmed & Concerned Activists & Cautious & Disengaged & Doubtful \\
\hline$N$ & 459 & 345 & 543 & 389 & 201 \\
\hline \multicolumn{6}{|l|}{ Demographics } \\
\hline Male (in \%) & 47.50 & 54.0 & 55.0 & 47.60 & 65.70 \\
\hline Age & 49.6 & $48.44^{b}$ & 50.2 & $52.54^{\mathrm{ab}}$ & $47.72^{\mathrm{a}}$ \\
\hline $\begin{array}{l}\text { Higher education } \\
\text { (in \%) (qualification for } \\
\text { university of applied } \\
\text { sciences or above) }\end{array}$ & 28.7 & 33.8 & 21.7 & 15.9 & 28.9 \\
\hline $\begin{array}{l}\text { Household income } \\
\text { ( } 3000 \text { Euros or more) } \\
\text { (in \%) }\end{array}$ & 24.8 & 34.0 & 24.5 & 12.4 & 31.3 \\
\hline Employment (in \%) & 53.8 & 67.3 & 63.5 & 46.1 & 64.7 \\
\hline Persons per household & 2.57 & 2.60 & $2.76^{\mathrm{a}}$ & $2.32^{\mathrm{ab}}$ & $2.95^{\mathrm{b}}$ \\
\hline At least I child (in \%) & 66.9 & 71.0 & 71.5 & 69.2 & 69.5 \\
\hline \multicolumn{6}{|l|}{ Media use' } \\
\hline TV use & $4.4 I^{\mathrm{a}}$ & 4.36 & $4.42^{\mathrm{b}}$ & 4.33 & $4.1 I^{a b}$ \\
\hline Radio use & $4.00^{\mathrm{a}}$ & $3.92^{\mathrm{b}}$ & 3.78 & $3.50^{\mathrm{ab}}$ & 3.69 \\
\hline Tabloids use & 2.85 & 2.63 & $2.90^{\mathrm{a}}$ & $3.02^{\mathrm{b}}$ & $2.39 \mathrm{ab}$ \\
\hline $\begin{array}{l}\text { Other daily newspaper } \\
\text { use }\end{array}$ & 3.89 & 3.92 & 3.83 & 3.70 & 3.62 \\
\hline $\begin{array}{l}\text { Weekly magazines and } \\
\text { newspapers use }\end{array}$ & $3.93^{\mathrm{ab}}$ & 3.72 & $3.62^{\mathrm{a}}$ & $3.5 \mathrm{I}^{\mathrm{b}}$ & 3.58 \\
\hline Internet use & $3.60^{\mathrm{ab}}$ & 3.50 & $3.20^{\mathrm{a}}$ & $3.02^{\mathrm{b}}$ & 3.25 \\
\hline $\begin{array}{l}\text { Conversations with } \\
\text { friends and family }\end{array}$ & $3.82^{\mathrm{abc}}$ & $3.66^{\mathrm{de}}$ & $3.40^{\text {af }}$ & $3.20^{\text {be }}$ & $2.95^{\mathrm{cdf}}$ \\
\hline Most reliable media & $\begin{array}{l}\text { TV (33.3\%) } \\
\text { Internet } \\
(17.8 \%)\end{array}$ & $\begin{array}{l}\text { TV }(27.8 \%) \\
\text { Weekly magazines/ } \\
\text { newspapers (I8.4\%) }\end{array}$ & $\begin{array}{l}\text { TV (46.2\%) } \\
\text { Internet } \\
(15.5 \%)\end{array}$ & $\begin{array}{l}\text { TV (44.1\%) } \\
\text { Internet } \\
(18.4 \%)\end{array}$ & $\begin{array}{l}\text { TV (37.3\%) } \\
\text { Internet } \\
(18.7 \%)\end{array}$ \\
\hline
\end{tabular}

Quality of most reliable source ${ }^{2}$

\begin{tabular}{llllll}
\hline Actuality & 4.39 & 4.29 & 4.36 & 4.25 & 4.31 \\
\hline Preciseness & $4.11^{\text {acd }}$ & $3.80^{\mathrm{ab}}$ & $3.86^{\mathrm{c}}$ & $4.06^{\mathrm{be}}$ & $3.75^{\mathrm{de}}$ \\
\hline Balance & 3.79 & 3.74 & 3.82 & 3.81 & 3.53 \\
\hline Truthfulness & $3.64^{\mathrm{a}}$ & 3.45 & $3.40^{\mathrm{a}}$ & 3.44 & 3.53 \\
\hline $\begin{array}{l}\text { Frequency of } \\
\text { researching information } \\
\text { about climate change }\end{array}$ & $3.17^{\mathrm{abc}}$ & $3.00^{\text {def }}$ & $2.67^{\mathrm{adg}}$ & $2.5 \mathrm{I}^{\mathrm{be}}$ & $2.34^{\mathrm{cfg}}$ \\
\hline
\end{tabular}

Figures are means if not otherwise indicated. Means in the same row that share superscripts differ at $p<.05$ in the posthoc test (Scheffé).

$N=1937$.

I"How often do you hear about climate change from these information sources?" I = never to $5=$ every week.

2"To what extent would you say that this characteristic applies to this source of information?" I = not at all to $5=$ very much.

3"How frequently do you seek information about climate change?" I = never to $5=$ very often. 
frequently for information about the issue and perceives television as the most reliable medium. Regarding all other types of mass media as well as interpersonal communication about climate change, the Cautious show average usage.

The Disengaged. This group is not only disengaged from the issue of climate change but also differs in other respects from other audience segments; $52 \%$ of the respondents are female, and with an average age of 53 years, they are significantly older than the Concerned Activists and the Doubtful. The Disengaged also have the smallest average household-size and low education levels, and more than half (53.9\%) are unemployed. Consequently, the Disengaged also have the lowest average income. This might also explain why they do not use cars and abstain from longer car or plane journeys: not out of concern about the environment (which is low), but because they cannot afford them.

The Disengaged do not seek information about climate change very often. If they do, they mainly use TV and tabloid newspapers, with all other media being used clearly below average. This group avoids media outlets that are more information-oriented and entail more complex reporting. In addition, this group barely talks about global warming.

The Doubtful. In this segment, the highest share of male respondents $(66 \%)$ can be found, with an average age of 48 years. Most work full-time, have a high income, and have one or more children, which might explain why they are skeptical about climate change yet still concerned about the environment: they are concerned about the limited resources on Earth and future generations.

People in this segment doubt climate change exists and scored the lowest on information seeking. They search for information about climate change significantly less frequently than the Alarmed, Concerned Activists, and Cautious. If this group receives such information at all, it reaches them via TV, the daily newspaper, or the radio. They believe that television and the Internet are the most reliable sources of information about climate change because these media outlets present information that is most up-to-date. Among the five audience segments, this segment talks the least about climate change with their family or friends.

\section{Summary and discussion}

The aim of our study was to establish whether the German population can be segmented into attitude types regarding climate change and to what extent these types differ in media use and information-seeking patterns. We show that the German public can be categorized into five types: the Alarmed, the Concerned Activists, the Cautious, the Disengaged, and the Doubtful.

In Figure 2, our results are compared to the US (Leiserowitz et al., 2009), Australian (Morrison et al., 2013), and Indian studies (Leiserowitz et al., 2013b), albeit with some caution. Since this study was a secondary analysis, we could not use the same items used in the US study and had to rely on cluster analysis, which was also used in the Indian study but not in the US or Australian studies (they used latent class analysis).

With these limitations in mind, the German population has the biggest group of Alarmed people among the four countries. Compared to Leiserowitz et al.'s (2009) study of the American public, the German audience is generally more concerned about climate change, as four out of the five audience segments show a higher-than-average concern about climate change.

In contrast, the Dismissive segment - which existed in the United States and Australia and believed most strongly that climate change is not occurring or not caused by humans - does not exist in Germany. Although the German Doubtful are also unconcerned about climate change, they still show concern for the environment in general (unlike the Dismissive in the United States or 


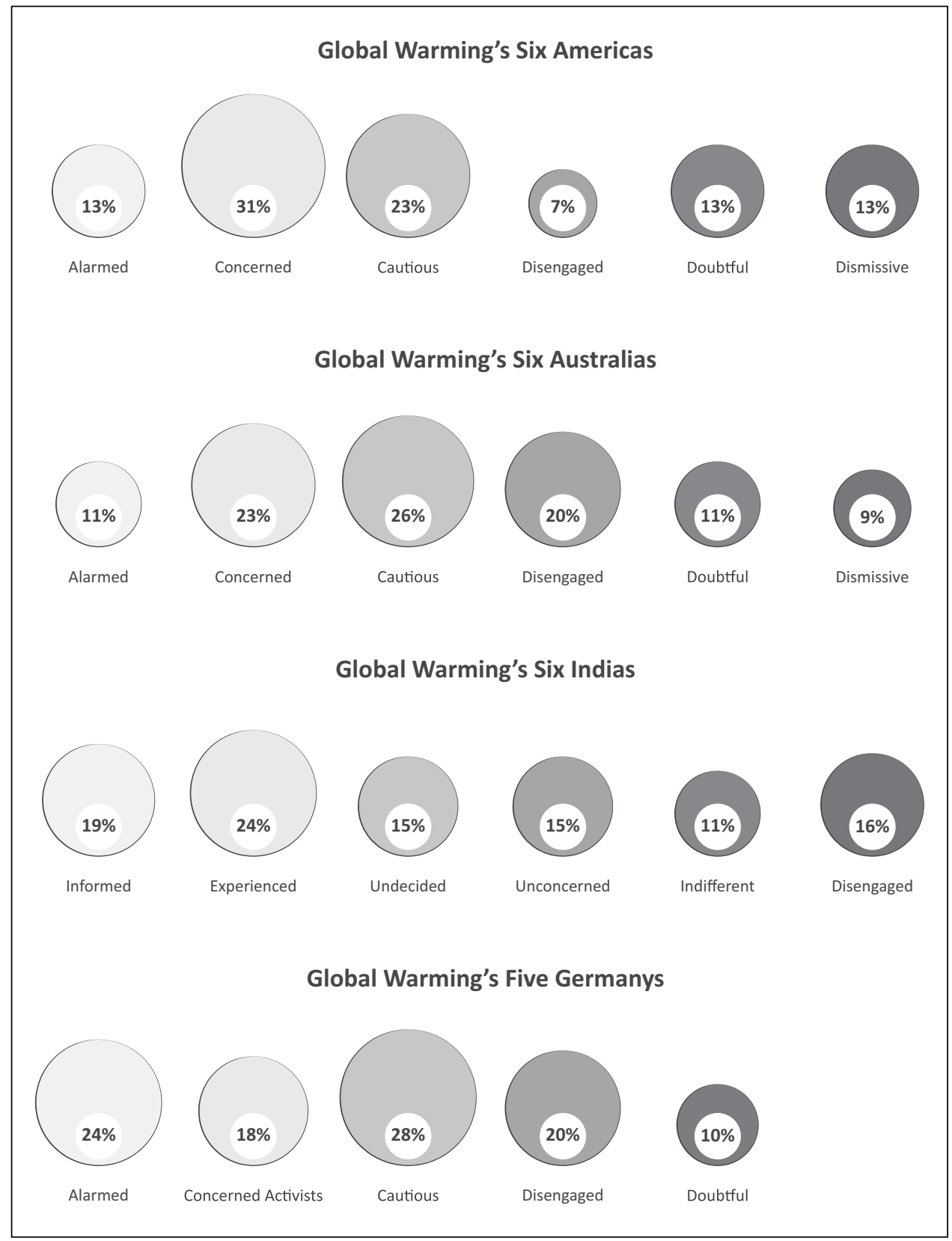

Figure 2. Audience segments in different countries (data are retrieved from Leiserowitz et al. (20I3b, 20I4) and Morrison et al. (20I3)). Comparability of the segments is limited as there are differences in survey items and data analysis between the countries.

Australia). This underscores that climate change skepticism is not as widespread in Germany as it is in Anglo-Saxon countries (Engels et al., 2013).

The differentiation of the public also holds true for the ways people get information about global warming. Although all types use television as the main source of information about climate 
change (Schäfer, 2012), the analysis shows that the Alarmed search for information in the mass media and talk about the issue most frequently. The Doubtful, in contrast, search least for climate change information. This is similar to the US results in which the Alarmed follow news on climate change closely and the Doubtful barely seek out information about the issue (Leiserowitz et al., 2009: 28).

These results are relevant not only for the scientific study of attitudes toward climate change. The results might also be useful for communication campaigns to raise people's awareness of and actions toward climate change, as they indicate the ways in which the different types must be addressed.

The three groups least concerned about climate change or least taking actions against global warming are the Doubtful, the Disengaged, and the Cautious. Although television is the main source of climate change information for these types as well, they still need to be addressed differently. With the Doubtful, a campaign on global warming should be aimed at raising their concern about climate change and reducing their doubts about ongoing global warming - a difficult task but perhaps not a completely hopeless endeavor, since this group shares a certain amount of environmental concern. The communication pattern of this type indicates that they do not look for information about climate change intentionally but come across it during their everyday, routine media use. They can be addressed if they are confronted with information about climate change unexpectedly on television, as "by-catch" while watching something else.

The Disengaged are not really skeptical about global warming. However, they do not engage much in environmentally friendly behavior, perhaps due to their lower social status, especially their low income. They should be addressed with basic information about climate change, since they are not well informed, in communication campaigns that are easily understandable and stress inexpensive methods for changing behavior. Since the Disengaged use tabloids, they might respond better to entertainment or fictional formats, such as movies like The Day after Tomorrow, which, however, tend not to have long-lasting effects (Hart and Leiserowitz, 2009; Leiserowitz, 2004). This group, however, may not be addressed at all through communication campaigns, because the Disengaged are not interested in the issue (cf. Hefner, 2013 for environmental protection). Behavioral changes among the Disengaged may have to be triggered by financial incentives, taxes, and so on.

The Cautious are aware of climate change as a problem but must be motivated to change their behavior accordingly. Communication campaigns should focus on mobilizing information and provide information about behavioral options in everyday life (e.g. refraining from using a car or using eco-power) to mitigate climate change. To increase this group's concern about the environment, information about environmental problems in general should be included.

People in one of the other two audience segments of the German public are more likely to be concerned about climate change. They look for information about climate change more frequently and could be addressed via multiple media outlets. Concern about global warming should be increased for the Alarmed in a campaign that focuses on inexpensive ways to behave environmentally friendly since this group is hesitant to use more expensive methods such as eco-power. These people could potentially function as opinion leaders as they talk about climate change quite often (they seem to mirror the "mediatized opinion leaders" on climate change found in Schäfer and Taddicken (2015)). A campaign should provide information about climate change that is easy to communicate further to other people.

The Concerned Activists are young and more affluent. These people are concerned about climate change but not as much about the environment in general. If a campaign convinces them of the broader environmental implications of climate change, their general environmental concern might increase, and these people might become even more engaged and could serve as role models for others. Information should be provided not only on television and the Internet but also in print media since these outlets are perceived as reliable and trustworthy. 
These findings are in line with recent studies on climate change-related attitudes in Germany (e.g. Engels et al., 2013; European Commission, 2014) and with attitude-based typologies on related issues such as the environment (Hefner, 2013). Still, these findings must be confirmed in the future since our study has several limitations. We could not operationalize all dimensions that might have been relevant. For example, it would have been useful to know whether the different segments use media more for information or entertainment. In addition, further information about the kind of people they talk to about global warming would also be relevant, since conversations with family and friends might differ from conversations with colleagues at work. In a similar fashion, a more differentiated study of what kind of information citizens use on the Internet would have strengthened the analysis. The next step should be to actually test the use and effects of information about climate change for these different audience segments to analyze if communication effects also differ between the types of climate change attitudes.

\section{Funding}

The author(s) disclosed receipt of the following financial support for the research, authorship, and/or publication of this article: The data used in this study was funded by by the German Research Council DFG through the Cluster of Excellence "Integrated Climate System Analysis and Prediction (CliSAP)", EXC 177, University of Hamburg.

\section{Notes}

1. The data contained some over- or under-representations. Therefore, some cases were weighted: people over 60 years were slightly underrepresented (33.7\% in the data vs $38.4 \%$ in the German population), women were slightly overrepresented $(55.1 \%$ vs $51.3 \%)$, and people with a tertiary education were overrepresented $(20.5 \%$ vs $9.5 \%)$.

2. The sample size was reduced because only cases with no missing variables have a factor value attributed. The reduced sample was checked for skewed distributions of variables, which ensured that the remaining sample was not biased in any direction.

3. The Ward method was also used in the Six India's study (Leiserowitz et al., 2013b). The US and Australian typologies, however, are based on latent class analysis, which must be taken into account when the results of this study are compared.

4. We organized our typology primarily along these attitude types instead of, for example, Germans' willingness to act upon climate change. This mirrors the US, Australian, and Indian studies. However, it must be emphasized that even if the segments have similar names, differences between the countries' segments remain. For example, the belief that climate change is occurring is stronger in the Alarmed, Concerned, and Cautious groups in Australia than in the same segments in the United States (Morrison et al., 2013).

\section{References}

Ajzen I (1989) Attitude structure and behavior. In: Pratkanis AR, Breckler SJ and Greenwald AG (eds) Attitudes and Persuasion, vol. 3. Hillsdale, NJ: Erlbaum, pp. 241-274.

Arlt D, Hoppe I and Wolling J (2011) Climate change and media usage: Effects on problem awareness and behavioral intentions. International Communication Gazette 73(1-2): 45-63. DOI: 10.1177/1748048510386741.

Bamberg S and Möser G (2007) Twenty years after Hines, Hungerford, and Tomera: A new meta-analysis of psycho-social determinants of pro-environmental behaviour. Journal of Environmental Psychology 27(1): 14-25. DOI: 10.1016/j.jenvp.2006.12.002.

Brosius F (2013) SPSS 21. Heidelberg: mitp.

Cabecinhas R, Lázaro A and Carvalho A (2008) Media uses and social representations of climate change. In: Carvalho A (ed.) Communicating Climate Change. Braga: CECS/Universidade do Minho, pp. 170-189.

Diekmann A and Preisendörfer P (2003) Green and greenback: The behavioral effects of environmental attitudes in low-cost and high-cost situations. Rationality and Society 15(4): 441-472. DOI: 10.1177/1043463103154002. 
Donk A, Metag J, Kohring M and Marcinkowski F (2012) Framing emerging technologies. Risk perceptions of nanotechnology in the German press. Science Communication 34(1): 5-29.

Engels A, Hüther O, Schäfer M and Held H (2013) Public climate-change skepticism, energy preferences and political participation. Global Environmental Change 23: 1018-1027. DOI: 10.1016/j.gloenvcha.2013.05.008.

European Commission (2014) Special Eurobarometer 409: Climate Change. Available at: http://ec.europa. eu/public_opinion/archives/ebs/ebs_409_en.pdf

Hart PS and Leiserowitz AA (2009) Finding the teachable moment. Environmental Communication 3(3): 355-366. DOI: 10.1080/17524030903265823.

HefnerD(2013)“Wiekriegen wirsieins Boot?”Eine Typologie zurEntwicklung von Kommunikationsstrategien zur Förderung umweltschützen Verhaltens ["How do get them on board?" A typology to develop communication strategies to foster environmental-friendly behavior]. Medien \& Kommunikationswissenschaft 61(3): 387-405.

Leiserowitz A (2004) Before and after The Day After Tomorrow: A U.S. study of climate change risk perception. Environment 46(9): 22-37.

Leiserowitz A, Maibach E, Roser-Renouf C and Smith N (2009) Global Warming Six Americas 2009. Available at: http://environment.yale.edu/climate-communication/files/climatechange-6americas.pdf

Leiserowitz A, Maibach E, Roser-Renouf C, Feinberg G and Howe P (2013a) Global Warming's Six Americas: September 2012. Available at: http://environment.yale.edu/climate/publications/SixAmericas-September-2012

Leiserowitz A, Maibach E, Roser-Renouf C, Feinberg G and Rosenthal S (2015) Climate Change in the American Mind: March 2015. Fairfax, VA: George Mason University and New Haven, CT: Yale Project on Climate Change Communication, Yale University.

Leiserowitz A, Maibach E, Roser-Renouf C, Feinberg G, Rosenthal S and Marlon J (2014) Global Warming's Six Americas: October 2014. Fairfax, VA: George Mason University and New Haven, CT: Yale Project on Climate Change Communication, Yale University.

Leiserowitz A, Thaker J, Feinberg G and Cooper D (2013b) Global Warming's Six Indias. Available at: http:// environment.yale.edu/climate-communication/article/Global-Warming-Six-Indias

McCright AM and Dunlap RE (2011) Cool dudes: The denial of climate change among conservative white males in the United States. Global Environmental Change 21(4): 1163-1172. DOI: 10.1016/j.gloenvcha.2011.06.003.

Maibach EW, Leiserowitz A, Roser-Renouf C and Mertz CK (2011) Identifying like-minded audiences for global warming public engagement campaigns. PLOS ONE 6(3): e17571. DOI: 10.1371/journal. pone. 0017571 .

Morrison M, Duncan R, Sherley C and Parton K (2013) A comparison between attitudes to climate change in Australia and the United States. Australasian Journal of Environmental Management 20(2): 87-100. DOI: $10.1080 / 14486563.2012 .762946$.

Moser SC (2010) Communicating climate change. WIREs Climate Change 1(1): 31-53. DOI: 10.1002/wcc.11.

Nisbet MC and Myers T (2007) The polls trends: Twenty years of public opinion about global warming. Public Opinion Quarterly 71(3): 444-470. DOI: 10.1093/poq/nfm031.

O’Keefe DJ (1990) Persuasion. Newbury Park, CA: SAGE.

Peters HP and Heinrichs H (2008) Legitimizing climate policy: The 'risk construct' of global climate change in the German mass media. International Journal of Sustainability Communication 3: 14-36.

Sampei Y and Aoyagi-Usui M (2009) Mass-media coverage, its influence on public awareness of climatechange issues, and implications for Japan's national campaign to reduce greenhouse gas emissions. Global Environmental Change 19(2): 203-212. DOI: 10.1016/j.gloenvcha.2008.10.005.

Schäfer MS (2012) „Hacktivism“? Online-Medien und Social Media als Instrumente der Klimakommunikation zivilgesellschaftlicher Akteure ["Hacktivism?" Online and social media as tools of climate communication of civil actors]. Forschungsjournal Neue Soziale Bewegungen 25(2): 68-77.

Schäfer MS (2015) Climate change and the media. In: Wright JD (ed.) International Encyclopedia of the Social \& Behavioral Sciences, vol. 3, 2nd edn. Oxford: Elsevier, pp. 853-859. 
Schäfer MS and Taddicken M (2015) Mediatized opinion leaders: New patterns of opinion leadership in new media environments? International Journal of Communication 9. Available at: http://ijoc.org/index.php/ ijoc/article/view/2778/1351

Schäfer MS, Ivanova A and Schmidt A (2014) What drives Media attention for climate change? Explaining issue attention of Australian, German and Indian Print Media from 1996 to 2010. International Communication Gazette 76(2): 152-176. DOI: 10.1177/1748048513504169.

Schmidt A, Ivanova A and Schäfer MS (2013) Media attention for climate change around the world: A comparative analysis of newspaper coverage in 27 countries. Global Environmental Change 23(5): $1233-1248$.

Sherley C, Morrison M, Duncan R and Parton K (2014) Using segmentation and prototyping in engaging politically-salient climate-change household segments. Journal of Nonprofit \& Public Sector Marketing 26(3): 258-280. DOI: 10.1080/10495142.2014.918792.

Sütterlin B, Brunner TA and Siegrist M (2011) Who puts the most energy into energy conservation? A segmentation of energy consumers based on energy-related behavioral characteristics. Energy Policy 39(12): 8137-8152. DOI: 10.1016/j.enpol.2011.10.008.

Taddicken M (2013) Climate change from the user's perspective. Journal of Media Psychology 25(1): 39-52.

Taddicken M and Neverla I(2011) Klimawandel aus Sicht der Mediennutzer: Multifaktorielles Wirkungsmodell der Medienerfahrung zur komplexen Wissensdomäne Klimawandel [Climate change from the perspective of media users: A multifactorial effects model on media experience with the complex issue climate change]. Medien \& Kommunikationswissenschaft 59: 505-525.

UN News Centre (2014) Opening Remarks at 2014 Climate Summit. Available at: http://www.un.org/apps/ news/infocus/sgspeeches/statments_full.asp?statID=2355\#.VC5suxDKWno

Vicente P and Reis E (2007) Segmenting households according to recycling attitudes in a Portuguese urban area. Resources, Conservation and Recycling 52(1): 1-12. DOI: 10.1016/j.resconrec.2007.01.005.

Zhao X (2009) Media use and global warming perceptions: A snapshot of the reinforcing spirals. Communication Research 36(5): 698-723. DOI: 10.1177/0093650209338911.

\section{Author biographies}

Julia Metag is a senior research and teaching associate at the University of Zurich's Institute of Mass Communication and Media Research (IPMZ), Switzerland. Her research focuses on political communication, science communication, and media effects.

Tobias Füchslin is a Student Associate at the University of Zurich's Institute of Mass Communication and Media Research (IPMZ). His interests are science communication, statistical analysis, and scientific methodology.

Mike S. Schäfer is Professor for Science Communication at the University of Zurich's Institute of Mass Communication and Media Research (IPMZ). His research focuses on climate change communication, online communication, and the mediatization of science. 